\title{
INTERAKSI BEBERAPA FAKTOR YANG BERPENGARUH TERHADAP HASIL TANGKAPAN PER UNIT USAHA ( CATCH PER UNIT EFFORT) ALBAKORA (Thunnus Alalunga Bonnaterre,1788) DI SAMUDRA HINDIA
}

\author{
Gussasta Levi Arnenda ${ }^{a, *}$, Fathur Rochman ${ }^{\text {a }}$ \\ ${ }^{a}$ Loka Riset Perikanan Tuna, Jln. Mertasari No 140, Sidakarya, Denpasar, Indonesia \\ *Koresponden penulis : gussastaarnenda@gmail.com
}

\begin{abstract}
Abstrak
Produksi sumber daya ikan akan selalu mengalami kenaikan dan penurunan secara alami. Perikanan tuna masih menjadi komoditas ekspor penting di Indonesia. Albakora merupakan spesies tuna yang selalu ada keberadaannya sepanjang tahun. Hasil tangkapan spesies ini adalah yang paling dominan dari spesies tuna lainnya. Pemahaman yang baik tentang interaksi berbagai faktor musim, daerah penangkapan, jumlah pancing antar pelampung dan kombinasi umpan sangat berguna untuk menentukan strategi penangkapannya. Penelitian ini bertujuan untuk menentukan strategi penangkapan dalam upaya penangkapan albacore yang efektif dan efisien. Penelitian dilakukan sepanjang bulan Januari 2006 sampai dengan Oktober 2015 melalui metode pengamatan dan pencatatan spesies albakora secara langsung oleh obsever diatas kapal longline yang berbasis di pelabuhan perikanan muara baru (Jakarta), Pelabuhan ratu (Jawa Barat), Cilacap (Jawa Tengah), dan Benoa (Bali). Hasil penelitian diperoleh faktor umpan memiliki pengaruh terbesar daripada seluruh faktor. Interaksi terbesar adalah antara daerah penangkpan dengan umpan. Pada faktor musim, musin muson barat dan muson timur tidak memiliki pengaruh yang signifikan. Faktor darah penangkapan, diluar ZEE memiliki nilai rata-rata CPUE lebih tinggi dari didalam ZEE. Faktor jumlah pancing antar pelampung tidak memiliki pengaruh yangsignifikan. Faktor umpan, ikan layang memiliki nilai signifikan tertinggi. Interaksi dari beberapa faktor terhadap CPUE hasil tangkapan ALB diketahui bahwa faktor umpan memiliki pengaruh terbesar daripada faktor lainnya, dan interaksi yang paling berpengaruh adalah interaksi anatara faktor umpan dengan faktor daerah penangkapan Strategi penangkapan dapat dilakukan pada daerah penangkapan diluar ZEE dengan umpan iakn layang, baik pada musim muson barat ataupun timur agar penangkapan ikan efektif dan efisien.
\end{abstract}

Kata Kunci: Catch per Unit Effort, Faktor Signifikan, Thunnus alalunga

\begin{abstract}
Production of fish resources will always increase and decrease naturally. Tuna fishery is still an important export commodity in Indonesia. Albacore is a tuna species that has always existed throughout the year. The catch of this species is the most dominant of other tuna. A good understanding of the interaction of factors: season, fishing grounds, Hook Between Float (HBF) and bait combinations is used for determining fishing strategies. This study aims to determine the strategy of arrest in an attempt to catch albacore. The study was conducted from January 2006 to October 2015 through the observation method and recording of albacore species directly by obsess on longline ships based at the Muara Baru fishing port (Jakarta), Pelabuhan Ratu (West Java), Cilacap (Central Java), and Benoa (Bali). The result of this research is that bait factor has the biggest influence over all factors. The biggest interaction is the fising ground with the bait. On the season factor. In seasonal factors, west season and east season have no significant effect. The fishing ground factor, outside of ZEE has a higher average CPUE value than in ZEE. The number of hook between float factors has no significant effect. Factor bait, layang have the highest significant value. The interaction of several factors to the ALB catch caught is known that the bait has the greatest influence over other factors, and the most influential interaction is the interaction between the bait factors and the fishing ground. The catch strategy can be carried out in the fishing ground area outside the ZEE with the layang bait, west season or east seasons for effective and efficient fishing
\end{abstract}

Keywords: Catch per Unit Effort, Signification Factor, Thunnus alalunga 


\section{PENDAHULUAN}

Produksi sumber daya ikan akan selalu mengalami kenaikan dan penurunan secara alami. Perikanan tuna masih menjadi komoditas ekspor penting di Indonesia. Ratarata hasil tangkapan per unit usaha Catch Per Unit of Effort (CPUE) pertahun digunakan untuk melihat gambaran kegiatan penangkapan ikan di suatu daerah penangkapan [1].

Albakora (ALB) (Thunnus alalunga) merupakan spesies tuna yang selalu ada keberadaannya sepanjang tahun. Hasil tangkapan spesies ALB adalah yang paling dominan dari spesies tuna lainnya [2]. ALB merupakan jenis ikan yang yang terdistribusi di perairan tropis dan subtropis (Collette \& Nauen 1983). Spesies ini mempunyai kemampuan termogulasi yang menyebabkan ALB menjadi perenang yang handal dan juga peruaya jauh (IOTC 2007). Hasil tangkapan spesies ini memiliki nilai potensi lestari mencapai lebih dari 40.000 ton tiap tahunnya (IOTC 2016). Hal ini dipengaruhi oleh berbagai macam faktor baik dari segi lingkungan ataupun dari teknik penangkapannya.

Faktor musim penangkapan, Indonesia memiliki 2 musim: musim muson barat dan musim musion timur. Musim muson barat memiliki kecepatan arus paling tinggi [3] dan terjadi pada kedalaman yang dangkal [4]. Musim muson timur memiliki kecepatan arus paling rendah[3], dan terjadi pada kedalaman yang dalam [4].

Faktor daerah penangkapan, ALB biasa tertangkap pada kedalaman 50-600 m pada suhu $10^{\circ}$ hingga $17^{\circ} \mathrm{C}$ (Beverly et al. 2003). Pemijahan ALB diperkirakan terjadi antara $10^{\circ}-30^{\circ}$ LS pada bulan OktoberJanuari [5]. Penangkapan spesies ini berada di luar perairan Zona Ekonomi Eksklusif (ZEE) Indonesia dan selatan Jawa Timur [6]

Faktor jumlah mata pancing antar pelampung merupakan faktor yang sangat penting untuk mendapatkan hasil tangkapan yang maksimum, ALB tertangkap pada kedalaman 100 - $400 \mathrm{~m}$ pada pancing No 6 [6].

Faktor umpan, penggunaan jenis umpan yang berbeda pada penangkapan ikan menggunakan alat tangkap longline di Samudra Hindia berpengaruh nyata terhadap hasil tangkapan tuna pada sore hari, dan tidak berbeda nyata pada pagi hari [7].

Puncak nilai CPUE ALB muncul pada tahun 2014 ketika kapal asing lebih dari 60 GT melakukan penangkapan dengan target tuna beku dan ALB. Tahun 2015 terdapat peraturan pelarangan kapal asing di Indonesia, sehingga CPUE ALB mengalami penurunan tajam. Faktor musim, jumlah pancing antar pelampung, dan daerah penangkapan mempengaruhi secara signifikan CPUE ALB [8]. Atas dasar inilah penelitian ini dibuat, untuk mengetahui seberapa besar interaksi faktor-faktor yang mempengaruhi hasil tangkapan ALB dengan mengetahui nilai signifikan masing-masing faktor, dengan penambahan faktor kombinasi umpan. Disamping itu penelitian ini juga bertujuan untuk menentukan strategi penangkapan dalam upaya penangkapan ALB untuk penangkapan supaya efektif dan efisien.

\section{METODE PENELITIAN}

Penelitian dilakukan sepanjang bulan Januari 2006 sampai dengan Oktober 2015 melalui metode pengamatan dan pencatatan spesies ALB secara langsung oleh observer diatas kapal longline yang berbasis di pelabuhan perikanan muara baru (Jakarta), Pelabuhan ratu (Jawa Barat), Cilacap (Jawa Tengah), dan Benoa (Bali). Data yang dikumpulkan berupa data total hasil tangkapan, spesifikasi alat tangkap, ukuran kapal, aspek operasional, dan daerah penangkapan ikan. Pengamatan dilakukan sebanyak 106 kali perjalanan (8.989 hari laut), sebanyak 2 perjalanan dari Muara baru, 4 perjalanan dari Pelabuhan ratu, 3 perjalanan dari cilacap, dan 97 perjalanan dari stasiun Benoa. Pada penelitian ini terdapat 2.381 sampel. Data yang diperoleh dianalisa dengan Generalized Linier Models (GLM) dan hasil yang berbeda nyata dilanjutkan dengan uji Duncan pada taraf signifikan $95 \%$.

\section{1) Nilai Catch per Unit Effort (CPUE)}

Analisis hasil tangkapan per unit usaha untuk kelimpahan ikan untuk long line dinyatakan dalam nilai laju pancing (hook rate) yaitu jumlah ikan/bobot ikan yang 
tertangkap per 100 mata pancing (Nasution 1993).

\section{2) Generalied Linier Models}

Faktor- faktor penting yang memiliki pengaruh terhadap CPUE) ALB dianalisis menggunakan GLM. Metode GLM adalah metode untuk menguantifikasikan antara faktor bebas (variabel respon) dengan faktor terikat (variabel predictor), penggunaan metode ini untuk menjelaskan perubahan nilai dari faktor besar apabila terdapat perubahan faktor bebasnya (Hapsari 2014).

GLM adalah metodologi untuk memodelkan hubungan antar faktor-faktor [9]. Dengan GLM, variabilitas dalam satu faktor dijelaskan oleh perubahan pada satu atau lebih faktor lainnya. Faktor yang dijelaskan disebut variabel "dependent" atau "response", sedangkan faktor yang melakukan penjelasan adalah variabel "explanatory", yang mejadi faktor variabel "dependent" atau "response yang dijelaskan adalah CPUE setiap tahun Faktor yang dijelaskan variabel "explanatory" adalah faktor-faktor yang berbengaruh dalam penangkapan ikan pada kapal long line. Sehingga akan mempengaruhi nilai CPUEnya.:

Faktor-faktor yang dimaksut dalam model GLM tersebut adalah:

\section{1). Musim penangkapan}

Yaitu faktor musim pada saat ALB tertangkap di Samudra Hindia. Faktor ini terbagi menjadi 2 macam kategori dimana Indonesia memiliki dua musim yaitu Musim Muson Barat (Bulan Desember sampai dengan Mei), dan Musim Muson Timur (Bulan Juni sampai dengan November )

2). Area penangkapan

Yaitu faktor dimana lokasi geografis (garis lintang dan garis bujur) ALB yang tertangkap. Area yang berada di dalam ZEE, dan area di luar ZEE (Gambar 1). Area di dalam ZEE $<15^{\circ} \mathrm{LS}$, dan diluar ZEE > $15^{\circ}$ LS. Pengelompokan area tebagi dalam $5^{\circ} \times 5^{\circ}$.

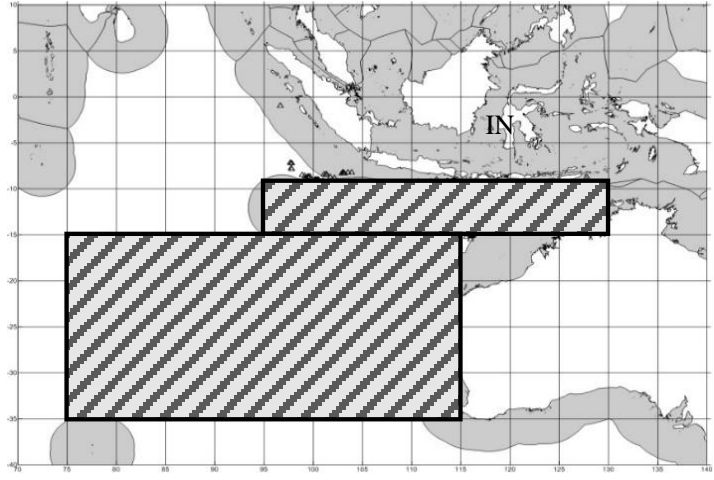

Sumber: [8]

Gambar 1. Sub-area yang digunakan untuk standarisasi CPUE berdasarkan observasi onboard 2006-2015 (Keterangan: sub-area 1 ada di dalam ZEE dan sub-area 2 berada di luar ZEE).

3). Jumlah pancing antar pelampung (Hook Between Float)

Yaitu faktor seberapa banyak jumlah pancing yang digunakan antar pelampung. Perikanan longline diperkenalkan pertama pada tahun 1930an oleh nelayan Jepang. Pada tahun 1939 di sana ada sekitar 70 kapal longline berukuran antara 60 hingga 270 Gross Ton (GT), dan terbagi menjadi 3 tipe yaitu small-scale(dibawah $15 \mathrm{~m}$ dan kurang dari $20 \mathrm{GT}$ ), medium-scale (15$25 \mathrm{~m}$, dan kurang dari $100 \mathrm{GT}$ ), dan besar (lebih dari $25 \mathrm{~m}$ dan lebih dari 100 GT). Small-scale mengoperasikan 3001000 pancing untuk 10 setting perharinya (3-10 pancing antar pelampung). Medium-scale mengoperasikan 12002500 pancing untuk 12 bagian per setting perharinya (10-12 pancing antar pelampung). Large-scale 2500-3500 pancing untuk 50-100 setting perharinya (>12 pancing antar pelampung) (Beverly, Chapman,and Sokimi 2003). Data yang tercatat terdapat variasi jumlah pancing antar pelampung, mulai dari 4 hingga 21 pacing antar pelampung. Pada faktor ini kapal longline yang digunakan unutk pengambilan data hanya medium-scale dan large-scale, sehingga faktor ini hanya dibagi menjadi 2 faktor yaitu jumlah pancing antar pelampung $\leq 12$, dan jumlah pancing antar pelampung $>12$. 


\section{4). Umpan}

Yaitu faktor dari komposisi umpan yang digunakan untuk melakukan penangkapan per-setting. Terdapat 6 spesies ikan yaitu: Lemuru, Sardinella spp. (LMR); Milkfish, Chanos chanos (MIL); Scad mackerel, Decapterus spp. (RUS); Gizzard shad, Anodontostoma chacunda (CHG); FrigateTuna, Auxis spp. (FRI); and Squid, Loligo spp. (CMI) [10]. Pada penelitian ini terdapat juga Cucut selendang biru, Prionace glauca Pc (BSH); Bawal hitam samudera, Bramidae (BWL); Lemadang, Coryphaena hippurus (CDF); Layur putih, Harriotta spp (HAR); Siro, Amblygaster sirm (SIRO), Ikan Setan sisik berduri, Ruvettus pretiosus (OIL), Ikan Setan coklat abu-abu, Lepidocybium (LEC). Kombinasi umpan setiap setting berbeda-beda, dari keseluruhan terdapat 23 komposisi persetting, sehingga faktor ini terbagi menjadi 23 faktor seperti pada table 1 .

Tabel 1. Faktor - faktor komposisi umpan yang digunakan

\begin{tabular}{|c|c|c|c|}
\hline BSH, LMR1 & $\begin{array}{l}\text { CMI, MIL, } \\
\text { RUS7 }\end{array}$ & LMR13 & $\begin{array}{l}\text { LMR, } \\
\text { RUS, } \\
\text { SIRO19 }\end{array}$ \\
\hline $\begin{array}{l}\text { BWL, CDF, } \\
\text { HAR, LMR2 }\end{array}$ & FRI8 & $\begin{array}{l}\text {.LMR, LEC, } \\
\text { MIL14 }\end{array}$ & MIL20 \\
\hline CHG, MIL3 & $\begin{array}{l}\text { FRI, LMR, } \\
\text { MIL9 }\end{array}$ & LMR, MIL15 & $\begin{array}{l}\text { MIL, } \\
\text { FRI21 }\end{array}$ \\
\hline CMI, LMR, MIL4 & $\begin{array}{l}\text { FRI, LMR, } \\
\text { RUS10 }\end{array}$ & $\begin{array}{l}\text { LMR, MIL, } \\
\text { RUS16 }\end{array}$ & $\begin{array}{l}\text { MIL,RUS } \\
22\end{array}$ \\
\hline $\begin{array}{l}\text { CMI, LMR, } \\
\text { RUS5 }\end{array}$ & FRI, MIL11 & LMR, OIL17 & RUS23 \\
\hline $\begin{array}{l}\text { CMI, LMR,MIL, } \\
\text { RUS6 }\end{array}$ & $\begin{array}{l}\text { FRI,MIL, } \\
\text { RUS12 }\end{array}$ & LMR, RUS18 & \\
\hline $\begin{array}{l}\text { Keterangan : } \\
\text { (BSH); Bawa } \\
\text { Lemadang, C } \\
\text { Harriotta spp } \\
\text { Ikan Setan sis } \\
\text { Setan coklat } \\
\text { Sardinella sp } \\
\text { (MIL); Scad } \\
\text { Gizzard shac } \\
\text { FrigateTuna, } \\
\text { (CMI). }\end{array}$ & $\begin{array}{l}\text { Cucut selen } \\
\text { l hitam s } \\
\text { oryphaena } \\
\text { (HAR); Si } \\
\text { ik berduri, } \\
\text { abu-abu, Le } \\
\text { p. (LMR); } \\
\text { mackerel } \\
\text { d, Anodon } \\
\text { Auxis spp. }\end{array}$ & $\begin{array}{l}\text { ig biru, Prior } \\
\text { udera, Bran } \\
\text { purus (CDF) } \\
\text { Amblygaster } \\
\text { vettus pretios } \\
\text { docybium (L } \\
\text { Milkfish, C } \\
\text { Decapterus } \\
\text { toma chact } \\
\text { RI); and Squi }\end{array}$ & $\begin{array}{l}\text { glauca Pc } \\
\text { a (BWL); } \\
\text { ayur putih, } \\
\text { (OIRO), } \\
\text { OIL), Ikan } \\
\text {; Lemuru, } \\
\text { os chanos } \\
\text { p. (RUS); } \\
\text { a (CHG); } \\
\text { Loligo spp. }\end{array}$ \\
\hline
\end{tabular}

\section{HASIL DAN PEMBAHASAN}

Nilai CPUE hasil tangkapan longline 2006-2015 mengalami kenaikan dan penurunan. Nilai rata-rata CPUE ALB 0.253 dengan kisaran antara 0.117-0.519 [8]. Nilai CPUE tertinggi terdapat pada tahun 2012.

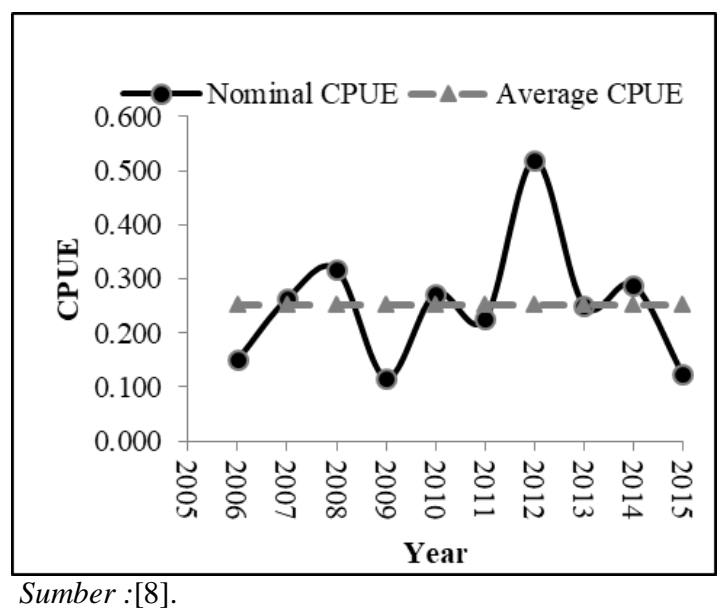

Gambar 2. Nilai rata-rata CPUE hasil tangkapan ALB pada tahun 2006 s.d. 2015.

Tingginya nilai CPUE merupakan pengaruh dari interaksi berbagai faktor yang terjadi. Keputusan Menteri Kelautan dan Perikanan RI Nomor 107/KEPMEN$\mathrm{KP} / 2015$ tentang rencana pengelolaan perikanan tuna, cakalang dan tongkol menyebutkan bahwa potensi sumberdaya tuna di WPP 572 dan 573, MSY albakora paling sedikit di WPP 572 dan WPP 573 yaitu sebesar 33.300 ton dengan status mengarah ke over fished. Sehingga spesies ini masih bisa dimanfaatkan.

Interaksi berbagai faktor perlu diketahui untuk mendapatkan faktor-faktor dan interaksi-interaksi yang mempengaruhi hasil tangkapan ALB yang signifikan. Hasil penelitian diperoleh 3 kombinasi faktor dan interaksi yang memiliki pengaruh signifikan terhadap CPUE. Nilai signifikan yang diperoleh juga sangat tinggi $0,000<0,05$ (sangat signifikan) dengan faktor umpan memiliki pengaruh paling tinggi dibanding faktor lainnya, hal ini terlihat dari nilai mse (mean square error) yang paling kecil pada umpan. Interaksi antar faktor paling signifikan terhadap CPUE adalah interaksi anatara daerah penangkapan dengan umpan, seperti pada tabel 2 berikut: 
Tabel 2. Interaksi antar faktor yang sigifikan terhadap CPUE.

\begin{tabular}{lrr}
\hline \multicolumn{1}{c}{ Source } & Mean Square & \multicolumn{1}{c}{ Sig. } \\
\hline daerah penangkapan & 13.659 & .000 \\
umpan & $\mathbf{2 . 2 2 8}$ & .000 \\
daerah penangkapan $*$ & 16.352 & .000 \\
umpan
\end{tabular}

Faktor-faktor yang berinteraksi masing-masing memiliki pengaruh terhadap CPUE, baik itu bernilai signifikan ataupun tidak. Faktor-faktor tersebuat adalah:

\section{Faktor Musim}

Penelitian sebelumnya diketahui bahwa nilai CPUE pada musim muson barat antara 0,075-0,716 dan pada musim muson timur 0,070-0,516 [8]. Hal ini menunjukan bahwa nilai rata-rata CPUE pada muson barat lebih tinggi dibandingkan dengan musim muson timur, namun tidak terlalu jauh perbedaannya. Nilai CPUE yang didapatkan mempresentasikan banyaknya hasil tangkapan ALB pada masing-masing musim penangkapan. Unutk lebih jelasnya dapat dilihat pada gambar 3 berikut:

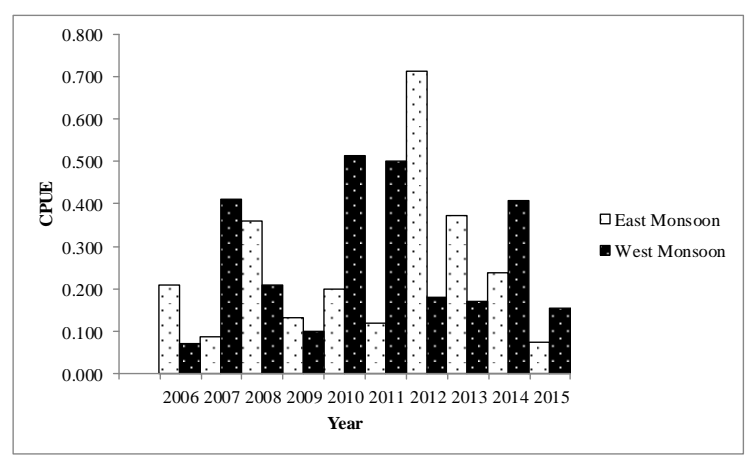

Sumber:[8].

Gambar 3. Nilai rata-rata CPUE musim penangkapan pada tahun 2005 s.d. 2015.

Hasil penelitian diperoleh bahwa perbedaan musim tidak berpengaruh signifikan terhadap CPUE. Namun, nilai ratarata CPUE pada dari musim muson barat $(0,253)$ lebih besar dari pada muson timur $(0,214)$. Pada Musim Barat kecepatan arus geostropik permukaan mencapai 0,013 $1,078 \mathrm{~m} / \mathrm{s}$, dan merupakan kecepatan geostropik tertinggi arus menuju arus bergerak ke timur [3]. Pada musim muson barat Mixed Layer Depth (MLD) menunjukan kedalaman paling dangkal antara 22 - 60 dbar. MLD paling dalam terjadi pada Musim Timur dengan nilai berkisar antara $60-100$ dbar. Pada musim muson barat angin bertip dari arah barat ke timur dengan suhu yang relatif hangat, pada musim muson timur terjadi sebaliknya Kedalaman MLD tersebut berkorelasi positif dengan hasil tangkapan tuna, dimana semakin dalam lapisan MLD semakin banyak hasil tangkapan tuna. Sedangkan semakin rendah suhu MLD justru menghasilkan penangkapan tuna yang semakin tinggi [4]. Penangkapan ALB pada musim muson barat (Desember -Mei) memiliki nilai signifikan yang tinggi dikarenakan nilai CPUE yang tinggi, sehingga hasil tangkapan pada musim ini sedikit lebih signifikan. Hasil penelitian menunjukan bahwa musim tidak memiliki nilai signifikan terhadap CPUE, sehingga untuk penangkapan bisa dilakukan pada musim muson timur dan musim muson barat.

\section{Faktor Daerah Penangkapan}

Nilai CPUE pada daerah penangkapan di luar ZEEI antara 0,026-0,289 dan di dalam ZEEI antara 0,032-0,973 [8]. Hal ini menunjukan bahwa nilai CPUE pada daerah penangkapan di luar ZEE lebih besar dibandingkan dengan didalam ZEE. Nilai CPUE yang didapatkan mempresentasikan banyaknya hasil tangkapan ALB pada masing-masing musim daerah penakapan. Untuk lebih jelasnya dapat dilihat pada gambar 4 berikut:

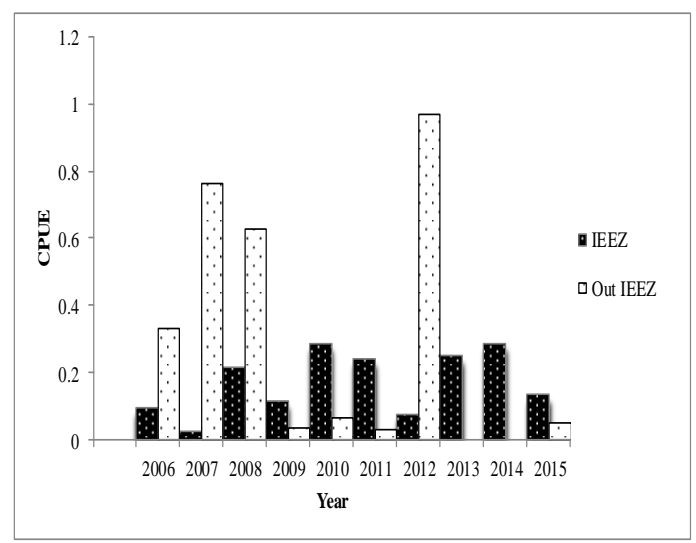

Sumber :[8]

Gambar 4. Nilai rata-rata CPUE musim penangkapan pada tahun 2005 s.d. 2015. 
Hasil penelitian diketahui adanya pengaruh faktor perbedaan daerah penangkapan terhadap CPUE denagn nilai $0,000<0,05$ (sangat signifikan). Hasil penelitian diperoleh rata-rata nilai CPUE di dalam ZEE $(0,167)$ lebih kecil daripada di luar ZEE $(0,582)$. Sehingga menunjukan daerah penangkapan diluar ZEEI lebih banyak hasil tangkapannya dibanding di dalam ZEEI.

Albakora merupakan jenis ikan yang yang terdistribusi di perairan tropis dan subtropis yang berada pada $50^{\circ} \mathrm{LU}$ sampai dengan $40^{\circ}$ LS (Collette, and Nauen 1983). Di Samudra Hindia, ALB yang belum matang gonad berada disebelah selatan $30^{\circ}$ LS, sedangkan yang telah matang gonad berada diperairan yang lebih hangat disebelah utara $30^{\circ}$ LS (Suda 1974). Pemijahan ALB diperkirakan terjadi antara $15^{\circ}-25^{\circ}$ LS di bagian timur Madagaskar dengan suhu diatas $24^{\circ} \mathrm{C}$ (Schaefer 2001). Dari batas ZEE dengan daerah distribusi dan pemijahan ALB, dapat diketahui bahwa ALB melakukan pemijahan diluar ZEE sehingga ALB diluar ZEE cenderung banyak dan berukuran kecil-kecil ada musi pemijahan. ALB di dalam ZEE bukan merupakan daerah pemijahan sehingga ALB yang tertangkap tidak terlalu banyak akan tetapi berukuran dewasa. Hal ini dikuatkan dengan kapal tuna longline Indonesia sebagian besar beroperasi diluar ZEE hook rate yang diperolaeh diluar zona ZEE lebih tinggi [11]. Untuk penangkpan yang berkelanjutan dan agar hasil tetap sigfikan

\section{Faktor Jumlah Pancing Antar Pelampung}

Hasil penelitian diperoleh bahwa interaksi antara jumlah pancing antar pelampung terhadap CPUE menunjukan tidak signifikan baik dengan jumlah pancing antar pelampung $\leq 12$ ataupun $>12$. Nilai rata-rata CPUE dengan jumlah pancing antar pelampung $\leq 12(0,217)$ lebih kecil dari jumlah pancing antar pelampung $>12$ $(0,253)$.

Hasil tangkapan ALB lebih didominasi pada lapisan renang permukaan hingga ke pertengahan [12]. Hal ini dipengaruhi karena keadaan lingkungan, misalnya parameter oseanografis seperti suhu, salinitas, densitas dan kedalaman lapisan thermoklin, arus dan sirkulasi massa air, oksigen dan kelimpahan makanan (Triharyuni, and Prisantoso 2012).

ALB yang tertangkap dipengaruhi oleh kedalaman pancing yang digunakan untuk menangkap, bukan berdasarkan dari jumlah pancing antar pelampung yang digunakan. Hal ini dibuktikan dengan kedalaman renang ALB berkisar antara 57,04 $-325,46 \mathrm{~m}$. Pada jumlah pancing antar pelampung 11, kedalaman mata pancing berkisar 61,31-196,28 $\mathrm{m}$ dan tertangkap pada pancing nomor 3/9 dengan nilai rata-rata kedalaman yaitu 138,16 m. Pada jumlah pancing antar pelampung 12, kedalaman mata pancing berkisar 65,72-213,18 m, pancing nomor 2/11 dengan nilai rata-rata kedalaman yaitu 115,89 m. Sedangkan dengan jumlah pancing antar pelampung 16, kedalaman mata pancing berkisar 57,04$351,78 \mathrm{~m}$ dan tertangkap pada pancing nomor $1 / 16$ dengan nilai rata-rata kedalaman yaitu $66,11 \mathrm{~m}$. ALB tidak pernah tertangkap pada pancing terdalam yaitu pancing nomor $8 / 9$ [12].

\section{Faktor Umpan}

Umpan adalah komponen yang sangat penting dalam operasi penangkapan ikan pada kapal tuna long line. Umpan harus selalu tersedia, dan umpan harus efektif untuk penangkapan spesies tuna yang ditargetkan, dan ekonomis. (Gopalakrishnan 1976 dalam Fitzgerald 2004). Faktor umpan secara umum berpengaruh signifikan terhadap nilai CPUE untuk jenis ikan tuna [10]. Kombinasi umpan juga sangat signifikan terhadap CPUE, kemudian dilakukan uji lanjutan dengan uji Duncan pada taraf signifikan $95 \%$.

Tabel 3. Hasil uji lanjutan nteraksi antar faktor tahun pennagkapan terhadap CPUE

$\begin{array}{ll}\text { Kombinasi } & \text { Duncan }{ }^{\mathrm{abc}} \\ \text { LMR, OIL } & 0.0000^{\mathrm{a}} \\ \text { BSH, LMR } & 0.0134^{\mathrm{a}} \\ \text { BWL, CDF, HAR, LMR } & 0.0176^{\mathrm{a}} \\ \text { CMI, MIL, RUS } & 0.0377^{\mathrm{a}} \\ \text { LMR, MIL, RUS } & 0.0774^{\mathrm{a}} \\ \text { FRI } & 0.0780^{\mathrm{a}} \\ \text { CMI, LMR, RUS } & 0.0866^{\mathrm{a}} \\ \text { CMI, LMR, RUS } & 0.0913^{\mathrm{a}}\end{array}$




\begin{tabular}{ll}
\hline FRI, MIL, RUS & $0.1008^{\mathrm{a}}$ \\
FRI, MIL & $0.1028^{\mathrm{a}}$ \\
LMR, MIL & $0.1279^{\mathrm{ab}}$ \\
LMR, RUS, SIRO & $0.1436^{\mathrm{ab}}$ \\
MIL, FRI & $0.1555^{\mathrm{ab}}$ \\
LMR, LEC, MIL & $0.1742^{\mathrm{ab}}$ \\
MIL, RUS & $0.1839^{\mathrm{ab}}$ \\
LMR, RUS & $0.2083^{\mathrm{ab}}$ \\
FRI, LMR, RUS & $0.2801^{\mathrm{ab}}$ \\
MIL & $0.3100^{\mathrm{ab}}$ \\
FRI, LMR, MIL & $0.3108^{\mathrm{ab}}$ \\
CMI, LMR, MIL & $0.3492^{\mathrm{ab}}$ \\
LMR & $0.3536^{\mathrm{ab}}$ \\
CHG, MIL & $0.5009^{\mathrm{ab}}$ \\
RUS & $0.8647^{\mathrm{c}}$ \\
\hline
\end{tabular}

Sig $a=0,078 ; b=0,52 ; c=1,000$

Hasil uji lanjutan menggunakan uji Ducan diperoleh bahwa ikan layang (Decapterus russelli) (RUS) merupakan kombinasi umpan yang menghasilkan nilai rata-rata CPUE tertinggi. Dibeberapa literatur kapal pennagkapan di Samudra Hindia cenderung menggunakan Bandeng hidup sebagai umpan pada tuna longline. Bandeng hidup merupakan umpan yang paling efektif [13]. Kapal penangkap tuna longline memilih menggunakan bandeng hidup sebagai umpan dikarenakan memiliki daya tahan yang lama dibandingkan dengan umpan lain dan mudah di tangani [14]. Ikan bandeng dapat menyesusaikan diri dengan lingkungan baru, seperti suhu, $\mathrm{pH}$, dan salinitas dengan metode aklimatisasi (Gusrina 2014). Sehingga bandeng masih bisa tetap bertahan hidup didalam air laut ketika digunakan sebagai umpan. Namun, hasil penelitian diperoleh bahwa nilai signifikan tertinggi terdapat pada kombinasi umpan ikan layang (RUS) dengan nilai 1,000 (sangat signifikan). Kombinasi penggunaan ikan layang hanya terdapat pada tahun 2014, sehingga dimungkinkan bahwa penggunaan kombinasi ini digunakan pada tahun yang tepat. Interaksi dengan umpan sangat siginifikan nilai $<0,05$ dipengaruhi oleh kombinasi umpan itu sendiri, dan kombinasi umpan dengan tahun. Penggunaan umpan layang pada sore hari memili pengaruh nyata terhadap hasil tangkapan ALB di Samudra Hindia[7].

\section{Interaksi Faktor Umpan Dan Daerah Penangkapan}

Hasil penelitian diperoleh bahwa interaksi antara faktor umpan dengan faktor daerah penangkapan memiliki nilai $0,000<$ 0,05 (sangat signifikan). Hal ini berarti bahwa ketika umpan dan daerah penangkapan memiliki pengaruh yang sangat kuat terhadap CPUE hasil tangkapan ALB. Pada faktor umpan, umpan ikan layang merupakan kombinasi umpan yang paling signifikan.Pada faktor daerah penangkapan ikan, daerah penangkapan diluar ZEE merupakan daerah penangkapan yang paling signifikan. Sehingga, interaksi penangkapan dengan menggunakan ikan layang dan daerah penangkapan di luar ZEE akan menghasilkan nilai CPUE terbesar.

\section{KESIMPULAN}

Interaksi dari beberapa faktor terhadap CPUE hasil tangkapan ALB diketahui bahwa faktor umpan memiliki pengaruh terbesar daripada faktor lainnya, dan interaksi yang paling berpengaruh adalah interaksi anatara faktor umpan dengan faktor daerah penangkapan Strategi penangkapan dapat dilakukan pada daerah penangkapan diluar ZEE dengan umpan iakn layang, baik pada musim muson barat ataupun timur agar penangkapan ikan efektif dan efisien. 


\section{UCAPAN TERIMA KASIH}

Penelitian ini dibiayai dari DIPA Loka Riset Perikanan Tuna T.A 2005 s.d T.A 2015. Penulis mengucapkan terima kasih kepada observer LRPT. Penulis mengucapkan terima kasih kepada Kementerian Kelautan dan Perikanan, Badan Riset dan Sumber Daya Manusia Kelautan dan Perikanan, dan kepada bapak Zulkarnaen Fahmi sebagai Kepala LRPT yang telah memberikan masukan yang berharga.

\section{DAFTAR PUSTAKA}

[1] A. A. Gemaputri, "Tingkat Pemanfaatan Sumber Daya Ikan Hasil Tangkapan Di Perairan Jember Utilization Rate Of Fish Resources In Jember Water," $J$. Perikan. (J., vol. (J. Fish., no. 1, pp. 3541, 2013.

[2] D. Novianto and B. Nugraha, "Komposisi Hasil Tangkapan Sampingan Dan Ikan Target Perikanan Rawai Tuna Bagian Timur Samudera Hindia Catch Composition of By-Catch and Target Species on Tuna Longline Fisheries in Eastern Indian Ocean Oleh:," Mar. Fish., vol. 5, no. 2, pp. 119-127, 2014.

[3] R. D. R, H. Setiyono, and M. Helmi, "Arus Geostropik Permukaan Musiman Berdasarkan Data Satelit Altimetri Tahun 2012-2013 Di Samudera Hindia Bagian Timur," J. Oseanografi NO 4, vol. 4, pp. 756-764, 2015.

[4] D. Teliandi et al., "Hubungan variabilitas mixed layer depth $\mathrm{k}$ riteria $\Delta$ $\mathrm{T}=0,5$ o $\mathrm{C}$ dengan sebaran tuna di Samudera Hindia bagian timur Relationship between variability mixed layer d epth $\Delta \mathrm{T}=0.5 \mathrm{o} \mathrm{C}$ criterion and distribution of tuna in the eastern Indian Ocean," vol. 2, no. 3, pp. 162-171, 2013.

[5] Z. Dhurmeea et al., "Reproductive Biology of Albacore Tuna (Thunnus alalunga) in the Western Indian Ocean," PLoS One, vol. 11(12), 2016.

[6] B. Nugraha and Setiya Triharyunir, "Pengaruh Suhu Dan Kedalaman Mata
Pancing Rawai Tuna (Tuna Long Line)

Terhadap Hasil Tangkapan Tuna Di Samudera Hindia," J. Penelit. Perikan. Indones., vol. Vol 15, No, pp. 239-247, 2005.

[7] A. Barata, A. Bahtiar, and H. Hartaty, "Pengaruh perbedaan umpan dan waktu setting rawai tuna terhadap hasil tangkapan tuna di Samudera Hindia," J. Penelit. Perikan. Indones., vol. 17.2, pp. 133-138, 2011.

[8] F. Rochman, B. Setyadji, and A. Wujdi, "Standardizing Cpue Of Albacore Tuna (Thunnus alalunga Bonnaterre, 1788 ) On Tuna Longline Fishery In Eastern Indian Ocean," Indonesian fisheries research journal, vol. 23, no. June, pp. 29-38, 2017.

[9] P. De Jong et al., Generalized Linear Models For Insurance Data, Vol. 10. Cambridge: Cambridge University Press, 2008.

[10] L. Sadiyah, N. Dowling, and B. I. Prisantoso, "Developing Recommendations For Undertaking Cpue Standardisation Using Observer Program Data," Indones. Fish. Res. Journal, vol. 18 No 1, no. 1996, pp. 577-588, 2012.

[11] Wudianto, K. Wagiyo, and B. Wibowo, "Sebaran Daerah Penangkapan Ikan Tuna Di Samudera Hindia," J. Penelit. Perikan. Indones., vol. 9, no. 7, pp. 1928, 2003.

[12] A. Bahtiar, A. Barata, and B. Nugraha, "Kedalaman Renang Dan Waktu Makan Ikan Albakora (Thunnus alalunga) Di Samudera Hindia Sebelah Selatan Jawa (Thunnus alalunga) In The Indian Ocean South Off Java," BAWAL, vol. 6, no. 2, pp. 89-94, 2014.

[13] W. J. FitzGerald, Milkfish Aquaculture In The Pacific: Potential For The Tuna Longline Fishery, no. April. Noumea, New Caledonia: Secretariat of the Pacific Community., 2004.

[14] N. A. Rangka and A. I. J. Asaad, "Teknologi budidaya ikan bandeng di sulawesi selatan," Pros. Forum Inov. Teknol. Akuakultur, no. 1995, pp. 187203,2010. 